\title{
Saudi Arabia's Electricity: Energy Supply and Demand Future Challenges
}

\author{
Fahad Al Harbi \\ Engineering Department \\ Lancaster University \\ Lancaster, UK \\ 0000-0003-2779-4683
}

\author{
Denes Csala \\ Engineering Department \\ Lancaster University \\ Lancaster, UK \\ 0000-0001-7450-5739
}

\begin{abstract}
This research examines the long-term future of the Kingdom of Saudi Arabia's power sector. The global energy sector has grown rapidly over the last decade and the Kingdom of Saudi Arabia's power sector is a part of this global trend. This growth requires the Kingdom of Saudi Arabia's power sector to achieve the target of load balance at the peak demand and consumption control. Therefore, this research identifies the relationship between peak load, consumption, and generation capacity, especially for the long-term during the growth and development of the Kingdom of Saudi Arabia's population. The electricity sector and the security of future energy need to be carefully considered. The electricity sector requires development of energy efficiency, upgrading all power systems and energy facilities to control electricity consumption. The availability of renewable energy resources and the strategic location of the Kingdom support the government's vision 2030 as a plan for the future of energy sector, which proposes opportunities to apply new technologies such as Renewable Energy and energy storage to comply with future requirements.
\end{abstract}

Keywords-Peak Demand, Power Consumption, New technologies, Future Energy Sector, Saudi Arabia.

\section{INTRODUCTION}

The Kingdom of Saudi Arabia's government applied a new long-term strategy for the future Vision 2030, which was announced on 25 April 2016, that emphasises the obstacles to meeting the future's growing requirements. The Council of Saudi Economic and Development Affairs developed the historic vision 2030 which aimed toward a number of goals and reform strategies for the Kingdom's long-term economic prosperity. The council's vision included reduced subsidies and reforms to several industries, established to cover all sectors of Saudi Arabia's economy including the energy sector. Electricity demand is dramatically increasing in Saudi Arabia, with peak load expected to grow at a rate of approximately seven percent per year over the coming decade [1]. The Kingdom's energy plan is to eliminate oil spillage, to reduce subsidies by increasing the energy tariff in several stages over next ten years, and to conduct a large-scale energy reform to re-evaluate all the energy resources. In addition, the Saudi's government plans to build more efficient electricity consumption control in the Kingdom with by concentrating on reductions in consumption during periods of high demand. In early 2016, the Kingdom government began its plan to reform energy prices as the first phase of a policy which will lead to reduce the energy consumption [2], although the prices increased from a very low base level and were still significantly below the global energy prices' level (Table I and II) and were acceptable to the public [2]. In early 2018, the Kingdom government went through the second phase of the energy programme including the Value Added Tax (VAT) implementation which was more challenging for the electricity sector [2]. The Electricity Tariffs $(\mathrm{SR} / \mathrm{kWh})$ rate was raised by 250 percent at the beginning of 2018 compared with the 2015 cost of $(\mathrm{SR} / \mathrm{kWh})$ which was the real challenge for the residential sector, especially for the consumer who used more than $6,000(\mathrm{kWh} / \mathrm{month})$ [2]. The residential sector is the main electricity consumer, constituting 50 percent of total consumption. Increased electricity tariffs did not affect the government and industry sectors, avoiding the impact of pursuing non-oil growth (Table I).

The Future Vision 2030 strategy addressed the residential sector's challenges before the actual application of the new electricity tariffs during the second phase of the effective programme by introducing the cash transfer programme (Citizen's Account) at the beginning of 2017 and applying it before the electricity tariffs increment. The cash transfer programme (Citizen's Account) was found to support and protect low and middle-income Saudi citizen households from the direct and indirect impacts expected from various energy sector reforms that may create additional burdens for certain segments of Saudi society. In order to control electricity consumption and energy management, the Kingdom government reconstructed and rehabilitated several

TABLE I. TABLE Electricity PRICES, SOURCE: MEES, [2].

\begin{tabular}{|c|c|c|c|}
\hline \multirow{2}{*}{ Sector } & \multicolumn{3}{|c|}{ (SR and \$ /kWh) } \\
\cline { 2 - 4 } & $\begin{array}{c}\text { End-2015 } \\
\text { Start-2018 }\end{array}$ & \% Change \\
\hline $\begin{array}{c}\text { Residential: } \\
1-6,000 \\
\mathrm{kWh} / \text { month }\end{array}$ & $\begin{array}{c}0.05 \\
(\$ 0.014)\end{array}$ & $\begin{array}{c}0.18 \\
(\$ 0.048)\end{array}$ & 260 \\
\hline $\begin{array}{c}\text { Residential : } \\
\text { above 6,000 } \\
\mathrm{kWh} / \text { month }\end{array}$ & $\begin{array}{c}0.30 \\
(\$ 0.08)\end{array}$ & $\begin{array}{c}0.30 \\
(\$ 0.08)\end{array}$ & 0 \\
\hline Industry & $\begin{array}{c}0.18 \\
(\$ 0.048)\end{array}$ & $\begin{array}{c}0.18 \\
(\$ 0.048)\end{array}$ & 0 \\
\hline Government & $\begin{array}{c}0.32 \\
(\$ 0.085)\end{array}$ & $\begin{array}{c}0.32 \\
(\$ 0.085)\end{array}$ & 0 \\
\hline
\end{tabular}


organizations such as the Electricity and Cogeneration Regulatory Authority (ECRA) and Saudi Energy Efficiency Center (SEEC) [3], [4]. The organizations updated their programs to play a greater role in the rationalizing of production and the reduction of consumption to unify efforts in the electricity field to comply with the Future Vision 2030 reform plan. The Saudi Energy Efficiency Center (SEEC) conducted a broad awareness campaign to educate the public about consumption reduction methods by issuing leaflets, preparing workshops that explain how to select the appropriate electrical equipment, and insisting that sales outlets adhere to the required specifications for consumption reduction [4].

In addition to the previous effective reforms implemented by energy programs, the Kingdom government launched the National Renewable Energy Program (NREP) as an essential long-term program in Future Vision 2030 which aims to substantially increase renewable energy's share in the total energy mix with carbon reduction [5]. The NREP generation target is 54 gigawatts (GW), $3.45 \mathrm{GW}$ by 2020 as the first phase during the National Transformation Programme (NTP) 2020 and $9.5 \mathrm{GW}$ by 2023 as the second phase, towards which Vision 2030 will increase renewables' share in the energy mix from zero to four percent [5]. Furthermore, the Kingdom government issued permission to households to install solar power systems. These are the main factors and techniques which were integrated into the system planning processes to achieve the Future Vision 2030 results which will shape the Kingdom's future. Although there are still several obstacles facing energy consumption reduction, the Kingdom's ambitious reform programmes are progressing in the right direction. The economic reforms and development, including in the energy sector, have achieved large popular approval, enabling the Kingdom of Saudi Arabia to comply with its Vision 2030.

TABLE II. TABLE INTERNATIONAL PRICES COMPARED WITH SAUDI FULL PRICES [8].

\begin{tabular}{|c|c|c|}
\hline \multicolumn{3}{|c|}{ Full Types Prices (\$/MMBtu) During 2015 } \\
\hline Fossil energy source & $\begin{array}{c}\text { Price paid by electricity } \\
\text { producers }\end{array}$ & $\begin{array}{c}\text { International } \\
\text { prices }\end{array}$ \\
\hline Natural gas & 0.75 & 9.04 \\
\hline Crude oil & 0.73 & 19.26 \\
\hline Diesel fuel & 0.67 & 21.67 \\
\hline Heavy fuel oil & 0.43 & 15.43 \\
\hline
\end{tabular}

\section{ELECTRICITY LOAD AND CONSUMPTION}

The peak load has surged over the past decade in the Kingdom of Saudi Arabia, contributing to the Kingdom of Saudi Arabia's historical profile of facing the most challenges in the electricity sector which should be balanced with the generation side. According to ECRA and previous studies, the Kingdom of Saudi Arabia's electricity demand has been growing at a significant rate which increased around seven percent from 2013 to 2014 [3] , [6]. The three main sectors (residential, industrial, and commercial) caused the growth in

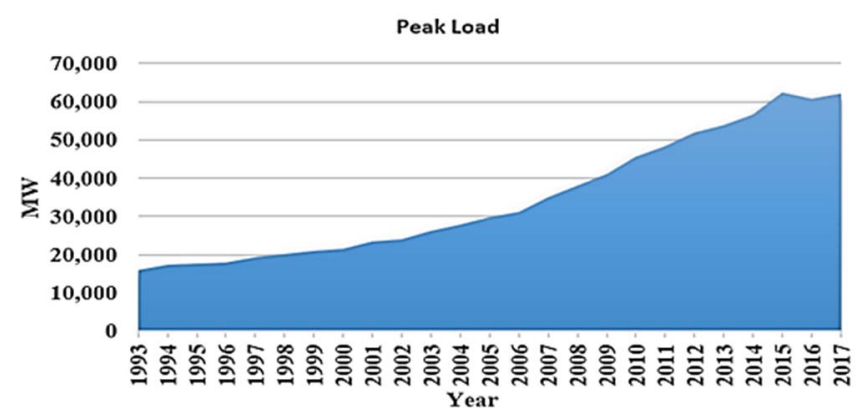

Fig. 1. Peak load in Saudi Arabia.

annual demand rate [3]. The peak load during 2015 reached $62.260 \mathrm{GW}$, raising by 10.1 percent, which was the highest value recorded in the history of the Kingdom [3]. The peak load reached $60.828 \mathrm{GW}$ in 2016 with a decreasing rate of 2.30 percent and $62.121 \mathrm{GW}$ in 2017 with a 2.1 percent grossing rate. Fig. 1, presents significant progress in the Kingdom of Saudi Arabia peak load during the last 28 years. The consumption followed the same method of increasing during the past 18 years especially from 2012 to 2017. 240.3 TWH was recorded in 2012 with an increased grossing rate around 9.3 percent. Before that, in 2003, the rate reached 10.54 percent as shown in Fig. 2 [3]. Electrical consumption continued rising during the last five years, reaching 294.612 TWH in 2015 with a grossing rate of 4.8 percent then 296.673 TWH in 2016 with a rate of 0.7 percent and 298.439 TWH in 2017 [3] , [7]. The highest increase in consumption was recorded in 1994 at a rate of 11 percent and the lowest decreasing rate in the history of the Kingdom in 2017, at 0.6 percent [3].

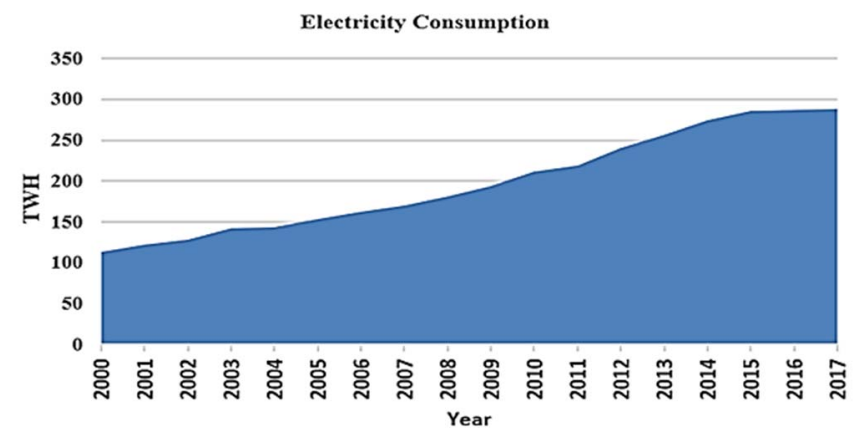

Fig. 2. Electrical consumption in Saudi Arabia.

\section{CONSUMPTION INCREASING FACTORS}

There are several factors that may cause the problem of increasing energy consumption in the Kingdom of Saudi Arabia such as low energy prices, the impact of a hot climate, technical reasons, and lack of public awareness. All of these elements encourage more energy consumption [8]. Electricity prices in the Kingdom are still very low compared to standard 
regional and global prices, leading to plenty of consumption. On the other hand, the Kingdom's government provided energy subsidies which undoubtedly represent a heavy burden for the Saudi economy. The total subsidies were \$107 billion, around 13.2 percent of the gross domestic product (GDP) in 2015 [9]. Energy sold during 2016 was divided as 50 percent consumed by the residential sector, 16 percent consumed by industrial consumers, 16 percent by the commercial sector, 14 percent by the government, and 4 percent by other consumers [10]. Losses in transmission lines and distribution stations constituted 10 percent of the total network's energy in 2010 and 9.4 percent during 2017. According to a research [8], the consumption is mainly used for the industrial, desalination, cooling, and domestic requirements in the Kingdom of Saudi Arabia. The hot and arid climate requires air conditioning and cooling systems especially during the summer from April to October which consumes more than 70 percent of the Kingdom's electricity, twice as much as the winter demand. The Kingdom depends on the sea as a drinking water source after treatment process in the desalination plants which are 30 desalination plants [8]. This number of desalination plants represents the largest number of facilities of any other country in the world, generating 18 percent of global desalinated water output. The Kingdom's government announced that they are planning to construct new desalination plants with a future investment target of $\$ 80$ billion during 2025, to boost desalinated water production from the current capacity of $3.6 \mathrm{~m} \mathrm{cu}$ meters to $8.5 \mathrm{~m}$ cu meters per day [10]. Around 60 percent of the water consumed by households is supplied by desalination plants with an increase of approximately 14 percent per year while groundwater aquifers provide the rest [8]. The treatment process for sea water is very costly, constituting 20 percent of the Kingdom's total energy consumption, and is not sustainable [8].

\section{A. Demographic Growth}

The Saudi General Authority for statistics reported that the Kingdom of Saudi Arabia had a total population around 32,552,336 million during 2017 while it was 31,742,308 million in 2016 with an average annual growth rate of 2.52 percent [11]. The Kingdom's population represents 65.1 percent in the Gulf Cooperation Council (GCC) as the Arabian Peninsula's largest nation [12]. Fast population growth reflects increasing demand for energy and other utilities. Unlike the general trend observed in most countries, the Kingdom of Saudi Arabia's energy consumption has been increasing at a faster pace than its GDP. The number of electricity customers doubled from 2.7 million in 1993 to 5.4 million in 2008 [3]. As the population grows, the number of electricity users increases; 8.6 million users were recorded in 2016 and 9.07 million in 2017 as shown in Fig. 3 [13]. The number of customers rose by 7.4 percent in 2000, the highest percentage recorded, and reached 5.4 percent in 2017 [3].
In addition, the kilowatt hour per customer was 25,689 KWh in 1990, 36,896 KWh in 2014, and decreased to 32,905 KWh in 2017 [3]. The KWh per capita in Saudi Arabia is highly inefficient in relation to population growth, necessitating a plan to reduce per capita electricity consumption. The Kingdom recorded $4422 \mathrm{KWh}$ per capita in 1993. This figure approximately doubled within 20 years, increasing to $8757 \mathrm{KWh}$ per capita in 2013. The numbers reached $9347 \mathrm{KWh}$ per capita in 2016 but decreased to 9167 KWh per capita in 2017, as shown in Fig. 4.

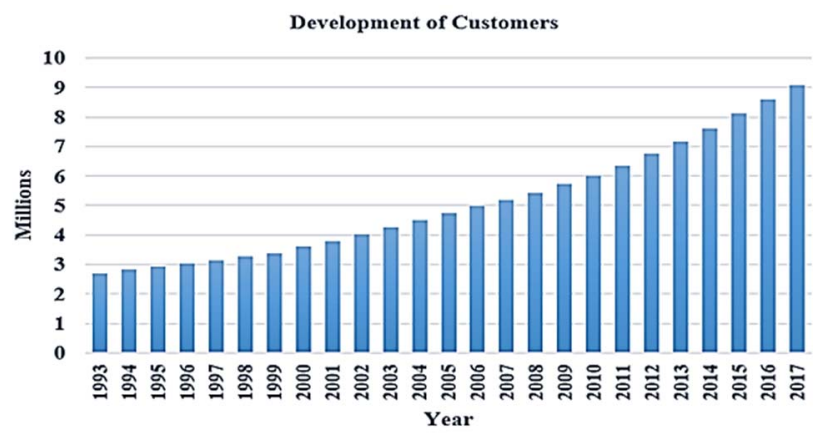

Fig. 3. Numbers of electricity customers in Saudi Arabia.

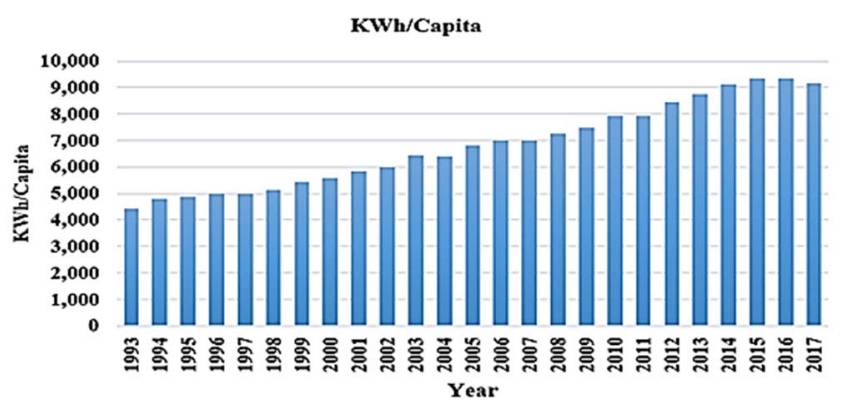

Fig. 4. The KWh per capita in Saudi Arabia.

\section{POWER GENERATION CAPACITY PERFORMANCE}

The generation side faces challenges in terms of economic growth and demographics. With demand rising rapidly faster than economic growth [14 ], the Kingdom must add more than four GW of power generation capacity per year [10]. Oil and gas have been the main energy sources used to generate electricity, and the Kingdom still burns oil to generate a significant proportion of its electricity. According to ECRA, the generation capacity in 2012 was $53.588 \mathrm{GW}$ and reached $58.462 \mathrm{GW}$ in 2013, then 65.506 GW in 2014 [3]. The generation and consumption sides are interrelated and must be balanced. During 2016, the Kingdom of Saudi Arabia's total generation capacity rose to $75 \mathrm{GW}$ with the Reregistering a Compound Annual Growth Rate (CAGR) in sales of 5.5 percent during the 2011-2016 period [10]. The main supplier of electricity in the Kingdom is the Saudi Electricity Company (SEC) which generates around 73 percent of the electrical power in the Kingdom. SEC managed to boost its installation capacity by adding a $4.7 \mathrm{GW}$ as 9.4 percent during 2016 [10]. In 2016 , the installation capacity reached more than $75.5 \mathrm{GW}$ 
and $77.3 \mathrm{GW}$ in 2017 , then climbed to approximately $80 \mathrm{GW}$ in 2018, as presented in Fig. 5 [3]. Furthermore, many of the Saudi Electricity Company's power plants were built and started its operation on service more than 25 years ago, so the company has been upgrading its units in order to increase efficiency [10]. The company started to convert the open cycle units to a combined cycle to increase the plant's efficiency from 33 percent to over 45 percent. During 2016, the company generated 24.6 percent of its total power from the combined cycle which was just 8.3 percent in 2010 [10].

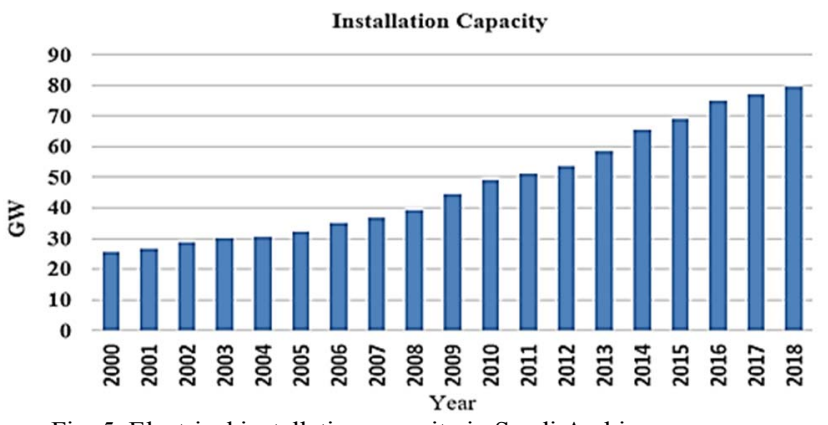

Fig. 5. Electrical installation capacity in Saudi Arabia.

According to the Electricity and Cogeneration Regulatory Authority (ECR), the Kingdom generated 337.5 TWh of electricity during 2016, up from 330.4 TWh during 2015. Increase in output over the previous 10 years had averaged 6.4 percent per year, below nominal GDP growth over the period from 2006 to 2016, which is considerably more than real GDP growth [10]. Furthermore, power demand continues to rise faster than either; the 2017 summer peak was lower than in 2016. Consumers may be curbing usage in anticipation of forthcoming tariff changes [10]. The power generated during 2017 reached 345.7 TWh [3].

\section{RESEARCH METHODOLOGY}

This research investigates load demand, power generation, and installation capacity in the Kingdom of Saudi Arabia over the long-term, as well as the Future Vision 2030 goals. Forecasting techniques will be applied to examine the future growth of the Kingdom's electricity sector in order to analyse the future of the power system and to measure the ability of the Kingdom's power sector to comply with demand variations. Applying forecasting techniques leads to reviewing multiple future scenarios which are important to the energy sector, such as peak load and high demand implications. In addition, all the collected data and references information were provided by reliable sources such as Saudi Electricity Company and ECRA. The collected data and gathered information were classified and re-analysed in order to obtain accurate findings with high quality. The energy data was divided into two main parts "load side data" and "supply side data" in order to clarify the relationship between the two sides. Moreover, the classification method aimed to verify the quality and reliability of the historical data in order to produce high accuracy future energy results with more credibility. Forecasting techniques and Group Method of Data Handling were employed in this research to analyse the electricity sector's future performance. The annual growth rate was calculated by the Compound Annual Growth Rate (CAGR) equation (1). Further, $\mathrm{f}$ is the final valve, $\mathrm{s}$ is the starting value and $y$ is the total numbers of years.

$$
C A G R=\left(\frac{f}{s}\right)^{1 / y}-1
$$

\section{RESEARCH RESULTS}

The prediction of the peak load as a future scenario was generated according to the historical data of the previous years, as illustrated in Fig. 6. The peak load reached 61690 MW during 2018, decreasing by 0.7 percent comparing to 2017. It is expected to increase to 66419 MW during 2021, with 7.6 percent growth compared to 2017. Furthermore, the peak load is expected to reach $74168 \mathrm{MW}$ in $2025,83855 \mathrm{MW}$ in 2030 and $103228 \mathrm{MW}$ in 2040. During 2011, forecasting research was conducted that found the peak load will grow by an annual rate of six percent from 2011 to 2021 while this research predicts three percent growth for the same period [1]. According to the two research [1] and [15], the peak load will reduce by 14 percent from 2017 to 2021, while this study predicts a seven percent increase for the same period, supported by the population growth rate and expected hot summer next years.

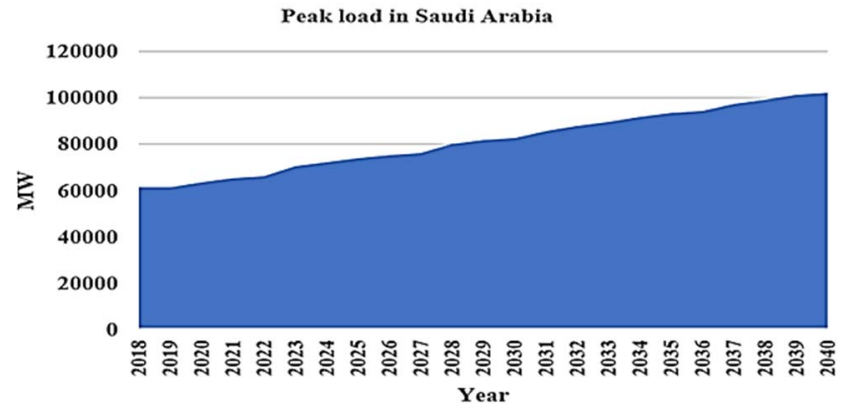

Fig. 6. Future scenario of peak load in Saudi Arabia.

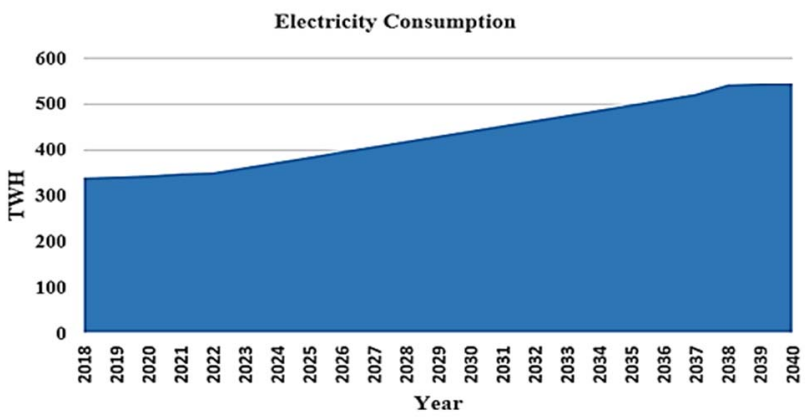

Fig. 7. Future scenario of electricity consumption in Saudi Arabia.

The forecast of the consumption shows that there will be a low rate of increase from 2018 to 2020 due to implementation of effective pricing and demand side 
management (DSM) programs. These programs decrease consumption not only during peak times, but during all hours of the day, which would also benefit the Kingdom's electricity consumption. Consumption will reach 339 TWh during 2018, 345 TWh in 2019, and 349 TWh in 2020 with a growth rate of 1.3 percent from 2018 to 2020 . In addition, consumption will reach $386 \mathrm{TWh}$ in 2025, $442 \mathrm{TWh}$ in 2030, and $556 \mathrm{TWh}$ during 2040 as presented in Fig. 7. Consumption will rise by an annual rate of 7.6 percent from 2015 to 2030 . Furthermore, the forecast shows faster growth of the consumption rate from 2026 to 2040 .

The number of customers as users of electricity (households) in the Kingdom of Saudi Arabia will be increasing from 2018 to 2040 period with an annual growth rate of 4.2 percent which was 6.4 percent in 2015 and 5.3 in 2017. According to this research, the number of customers is expected to reach 9.6 million in 2018 and around 11 million during 2021. In addition, it will rise to 13.3 million in 2025 and 16.6 million in 2030 until reaching 24.5 million during 2040, as presented in Fig. 8. The number of households registered as users of electricity in the Kingdom of Saudi Arabia are highly affected by the quick growth of the general population which increased by 2.52 percent from 2016 to 2017 , impacting the possibility of decreasing consumption per customer. On the other hand, the KWh per capita was 9167 $\mathrm{KWh}$ per capita in 2016 and expected to raise from $9167 \mathrm{KWh}$ during 2017 to $9576 \mathrm{KWh}$ in 2018 with a growth rate around 4.4 percent. Furthermore, it will reach $10207 \mathrm{KWh}$ per capita in 2021, then $11048 \mathrm{KWh}$ per capita in 2025 and $12099 \mathrm{KWh}$ per capita in 2030 until reaching $14201 \mathrm{KWh}$ per capita during 2040 as presented in Fig. 9. Annual growth will remain around two percent from 2018 to 2040, representing a decrease compared with the annual growth between 1990 and 2017, which was around three percent.

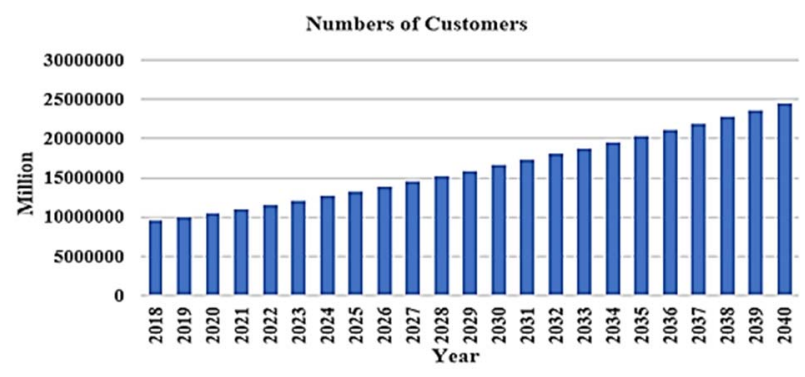

Fig. 8. Future scenario of number of customers in Saudi Arabia.

The prediction of the installation capacity shows significant development in future installation capacity which is required for the rapid growth of the household electricity consumption. Furthermore, installation capacity in 2018 is expected to be $84 \mathrm{GW}$ while it was $77.4 \mathrm{GW}$ in 2017 with a growth rate around 8.7 percent, and it will increase to $93 \mathrm{GW}$ in 2020 until reaching $122 \mathrm{GW}$ in 2025. According to this research, the installation capacity will achieve $158 \mathrm{GW}$ in 2030 and $243 \mathrm{GW}$ during 2040 with an annual growth rate

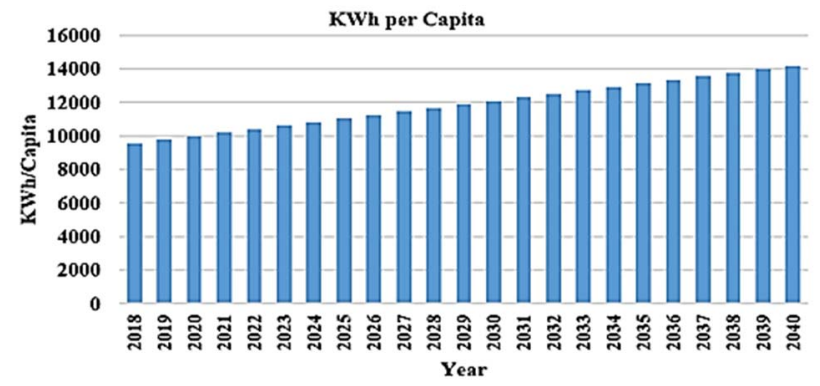

Fig. 9. Future Scenario of KWh per capita in Saudi Arabia.

around five percent from 2018 to 2040 as presented in "Fig. 10. In addition, the most important aspect is that the annual growth rate of installation capacity (five percent) is greater than the annual growth rate of electricity customers (4.2 percent) which supports the accuracy of this research's forecasting techniques. The power generated in 2016 was around 337.5 TWh and 345.7 TWh in 2017 while it is expected to achieve 368.6 TWh during 2018. Furthermore, 403.8 TWh of power is predicted to be generated in 2020, $489.5 \mathrm{TWh}$ in 2025, and 575.3 in 2030, until reaching 746.5 TWh during 2040 as shown in Fig. 11. The annual growth rate of power generation is 3.2 percent for the period from 2018 to 2040. The highest producer oil Saudi Arabia was consumed nearly a quarter of its oil production as a direct burning oil for power generation in the summer months in 2013 [16] , [17]. Forecasting accuracy is the most important aspect of studying all forms of energy generation to determine future behaviour challenges of installation capacity such as load balance, quality stability, and reliability in order to analyse their implications for the power system and the local environment. At the same time, the power supply and demand side are required to match on a second by second basis especially during the peak demand period.

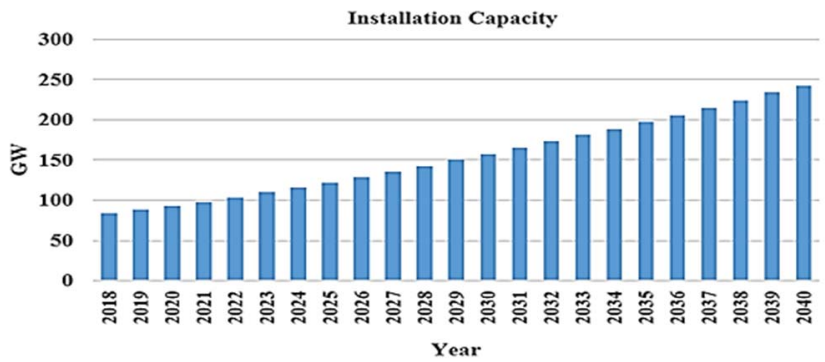

Fig. 10. Future scenario of installation capacity in Saudi Arabia.

Electricity Generated

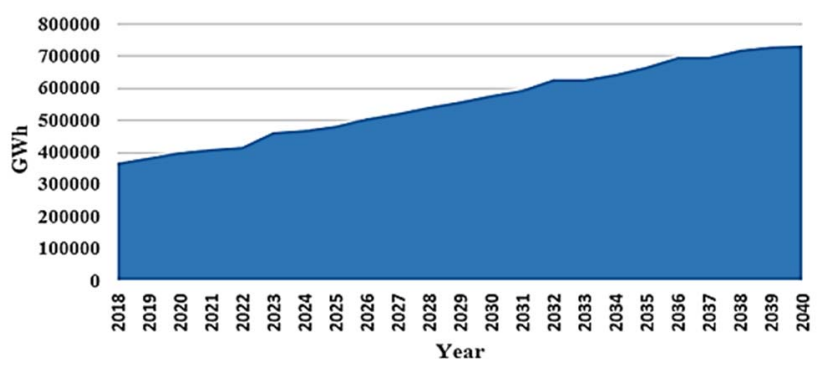

Fig. 11. Future scenario of electricity generation in Saudi Arabia. 


\section{CONCLUSION}

This research demonstrates the future scenarios of the Kingdom of Saudi Arabia's electricity sector and how the Kingdom can comply with future requirements. Therefore, this research identifies the relationship between the peak load, consumption, and the power generated for long-term growth of electricity customers in the Kingdom. The forecasting technique results highlight that the scenario shows significant increase in the peak load as 7.6 percent in 2021 compared with 2017. Furthermore, consumption is expected to rise by an annual rate of 7.6 percent from 2015 to 2030 due to the increasing population growth rate. According to this research, the number of customers and households in Kingdom of Saudi Arabia will increase by an annual growth rate of 4.2 percent between 2018 and 2040, with a two percent annual growth rate for the KWh per capita for the same period. In addition, 3.2 percent is predicted as the annual power generation growth rate for the period from 2018 to 2040 .

The electricity sector must develop the Energy Efficiency Programme at the consumer level especially for households, industry, and the commercial sector. All power systems and energy facilities should be upgraded in order to improve generation capacity. Finally, there are significant opportunities for the Kingdom's electricity sector to apply new technologies such as renewable energy to comply with future requirements.

\section{ACKNOWLEDGMENT}

The author Fahad Al Harbi is a PhD research student at Lancaster University and his scholarship is sponsored and supported by the Saudi Arabia's government - ministry of education.

\section{REFERENCES}

[1] A. Faruqui, R. Hledik, G. Wikler, D. Ghosh, J. Prijyanonda, and N. Dayal, "Bringing demand-side management to the kingdom of Saudi Arabia," The Brattle Group, 2011.

[2] Arab Petroleum Investments Corporation (APICORP), "APICORP Energy Research: Saudi Energy price reform getting serious," APICORP Group, Saudi Arabia,2018. [Online]. Available: http:/www.apicorp.org/Research/EnergyReseach/2018/APICORP_E nergy_Research_V03_N05_2018.pdf.

[3] Electricity and Cogeneration Regulatory Authority (ECRA). (2018, Nov. 01). Data and statistics [Online]. Available: http://ecra.gov.sa/en us/Pages/default.aspx .

[4] Saudi Energy Efficiency Center (SEEC). (2018, Nov. 02). Program's working fields. [Online]. Available: http://www.seec.gov.sa/en .

[5] National Renewable Energy Program (NREP). (2018, Nov. 04). Renewable energy [Online]. Available: https://www.ksaclimate.com/nrep .

[6] H. Albalawi, "Potential of Rooftop PV Systems on Weekly Peak Load Shaving in Saudi Arabia," Smart Grid and Renewable Energy, vol. 9, no. 02 , p. 33, 2018.

[7] BP Global Group, " BP Statistical Review of World Energy," BP Global Group, UK, 2018. [Online]. Available: https://www.bp.com/content/dam/bp/businesssites/en/global/corporate /pdfs/energy-economics/statistical-review/bp-stats-review-2018-fullreport.pdf.
[8] A. Demirbas, A. A. Hashem, and A. A. Bakhsh, "The cost analysis of electric power generation in Saudi Arabia," Energy Sources, Part B: Economics, Planning, and Policy, vol. 12, no. 6, pp. 591-596, 2017.

[9] S. Kerr, "Saudi Arabia Looks to Reform Energy Subsidy Program," Financial Times, vol. 12, 2015.

[10] Oxford Business Group (OBG), " Saudi Arabia Report: Saudi Arabia works to meet rising water and energy demand," Oxford Business Group (OBG), UK, 2018. [Online]. Available: https://oxfordbusinessgroup.com/.

[11] General Authority for Statistics. (2018, Nov. 04). Total dwellings occupied with Saudi households in Saudi Arabia [Online]. Available : https://www.stats.gov.sa/en/indicators/228.

[12] A. A. Salam, I. Elsegaey, R. Khraif, and A. Al-Mutairi, "Population distribution and household conditions in Saudi Arabia: reflections from the 2010 Census," SpringerPlus, vol. 3, no. 1, p. 530, 2014.

[13] Saudi Electricity Company (SEC). (2018, Nov. 11). Background on core business [Online]. Available : https://www.se.com.sa/enus/invshareholder/Pages/BackgroundOnBusinessSegment.aspx.

[14] H. M. S. Al-Maamary, H. A. Kazem, and M. T. Chaichan, "The impact of oil price fluctuations on common renewable energies in GCC countries," Renewable and Sustainable Energy Reviews, vol. 75, pp. 989-1007, 2017.

[15] D. Wogan, S. Pradhan, and S. Albardi, "GCC Energy System Overview - 2017," The King Abdullah Petroleum Studies and Research Center (KAPSARC), Saudi Arabia, 2017, [Online]. Available: $\quad$ https://www.kapsarc.org/research/projects/energyproductivity-in-the-gcc/.

[16] S. Griffiths, "Renewable energy policy trends and recommendations for GCC countries," Energy Transitions, vol. 1, no. 1, p. 3, 2017.

[17] H. M. S. Al-Maamary, H. A. Kazem, and M. T. Chaichan, "Renewable energy and GCC States energy challenges in the 21st century: A review," International Journal of Computation and Applied Sciences IJOCAAS, vol. 2, no. 1, pp. 11-18, 2017. 